\title{
Colopexia videoassistida com dois portais para o tratamento de prolapso retal recidivante
}

\author{
Two portal video-assisted colopexy for treatment of recurrent rectal prolapse
}

\author{
Rogério Luizari Guedes ${ }^{\mathrm{I}}$ Marcella Teixeira Linhares ${ }^{\mathrm{II}}$ Ialo Ferro de Castro Junior ${ }^{\mathrm{II}}$ \\ Caroline Posser SimeoniII ${ }^{\mathrm{II}}$ Thiago de Oliveira Cunha ${ }^{\mathrm{II}}$ Cristiano Gomes ${ }^{\mathrm{I}}$ Maurício Veloso Brun ${ }^{\mathrm{II}}$ \\ Ney Luis Pippi ${ }^{\text {II }}$
}

\section{- NOTA -}

\section{RESUMO}

O presente relato descreve a utilização da colopexia videoassistida por meio de dois portais de acesso em um caso de cão com prolapso retal recidivante. Após abordagem laparoscópica, o cólon descendente foi tracionado em sentido caudocranial, promovendo-se a redução do prolapso. $O$ acesso pré-púbico foi ampliado, exteriorizando-se o bordo antimesentérico do cólon, no qual se realizou incisão seromuscular de tamanho correspondente à realizada na parede muscular, criando uma ferida de aproximadamente $2,5 \mathrm{~cm}$ de extensão. A fixação à bainha muscular interna se deu através de sutura contínua simples empregando fio de ácido poliglicólico no 2-0. Não houve complicações no transoperatório, bem como indícios de recidiva ou episódios de tenesmo e disquesia após seis meses da intervenção cirúrgica. A colopexia videoassistida descrita é uma alternativa à técnica convencional na correção de prolapso retal recidivante em cães.

Palavras-chave: canino, cólon descendente, colopexia, videocirurgia.

\section{ABSTRACT}

This report describes a two portals video-assisted colopexy technique in a case of dog with recurrent rectal prolapse. After laparoscopic approach, the descending colon was pulled in a caudocranial direction to promote the prolapse reduction. The prepubic laparoscopic access was enlarged for the exteriorization of colon's antimesenteric border, which was incised in its seromuscular layer with a similar size of the muscular wall incision, creating a $2,5 \mathrm{~cm}$ wound. The colopexy on the internal muscular sheath was performed using a simple continuous pattern with 2-0 polyglycolic acid. There were no transoperative complications, as well as evidence of recurrence or episodes of tenesmus and dyschezia for at least six months after surgery. The video-assisted colopexy described is an alternative to the conventional technique of recurrent rectal prolapse treatment in dogs.

Key words: canine, colon, colopexy, videosurgery.

O prolapso retal é definido como a protrusão de mucosa a partir do ânus, sendo considerado completo aquele que envolve todas as camadas da parede retal em toda sua circunferência (HEDLUND \& FOSSUM, 2007). Está associado principalmente a animais jovens, com endoparasitismo ou enterites, mas pode ocorrer em cães e gatos de qualquer idade, sexo ou raça acometidos por afecções que provoquem tenesmo (WACHASK, 2002).

O tratamento e o prognóstico de prolapsos de reto dependem da causa, da extensão, cronicidade e da recorrência, sendo que em casos agudos recomendase a redução manual associada à sutura em bolsa de tabaco (HEDLUND \& FOSSUM, 2007). Nos casos de recidiva, é indicada a colopexia (WACHASK, 2002). Esta técnica é utilizada com o intuito de evitar os movimentos caudais do cólon e do reto, criando aderências permanentes entre as superfícies serosas do cólon descendente e a parede abdominal (HEDLUND \& FOSSUM, 2007). Como procedimentos alternativos

IPrograma de Pós-graduação em Medicina Veterinária, Universidade Federal de Santa Maria (UFSM), Santa Maria, RS, Brasil. "Curso de Medicina Veterinária, UFSM, Santa Maria, RS, Brasil.

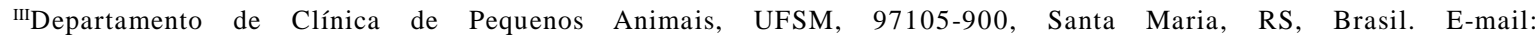
mauriciovelosobrun@hotmail.com. *Autor para correspondência. 
à colopexia convencional, destacam-se as técnicas por acesso laparoscópico e videoassistida, cuja viabilidade tem sido demonstrada em diferentes estudos (FREEMAN, 1998; BRUN et al., 2004a; BRUN et al., 2007a).

No que se refere às técnicas laparoscópicas pesquisadas para colopexia, há relatos de colopexia transparietal (BRUN et al., 2004b), além de procedimentos que incluem o uso de segmento de pericárdio homólogo conservado em glicerina a $98 \%$ (BRUN et al., 2007b) e o uso de tela de polipropileno (BRUN et al., 2007a). O presente relato busca descrever a utilização da colopexia videoassistida com dois portais de acesso na correção de prolapso retal recidivante em um cão, ocorrido após tratamento cirúrgico para divertículo anal.

Um cão da raça Dachshund, macho, oito anos de idade, apresentou tenesmo e disquesia após 28 dias de correção cirúrgica de hérnia perineal com divertículo anal, resultando em três episódios de prolapso de reto em intervalo de 15 dias. Após duas tentativas sem sucesso de reposição manual associada à aplicação de sutura em bolsa de tabaco, optou-se pela avaliação da condição retal e colopexia terapêutica, por meio de técnica laparoscópica videoassistida utilizando dois portais de acesso. Após tricotomia ampla, estendendo-se da cartilagem xifóide à região púbica e até a região média da parede abdominal lateral, o paciente foi posicionado em decúbito dorsal, utilizando álcool $70 \%$ e iodopolividona $1 \%$ para antissepsia do campo operatório. Procedeu-se à realização do primeiro portal através de incisão de pele de aproximadamente $11 \mathrm{~mm}$ sobre a cicatriz umbilical, realizando-se a introdução do primeiro trocarte $(11 \mathrm{~mm})$ pela técnica aberta. Após a insuflação com $\mathrm{CO}_{2}$ até obter uma pressão intra-abdominal de $12 \mathrm{mmHg}$, procedeu-se à inspeção da cavidade abdominal. Em seguida, foi introduzido, sob visão direta, um segundo trocarte $(11 \mathrm{~mm})$ na região paramediana pré-púbica esquerda a $2 \mathrm{~cm}$ da linha média, estabelecendo-se o segundo portal. O cólon descendente foi identificado e tracionado com pinça laparoscópica Babcock para promover a redução do prolapso (Figura 1A). Concomitantemente, um auxiliar de sala_colaborou externamente nesta redução e na manutenção temporária do posicionamento do cólon, antes de sua fixação definitiva. Foram observados pequenos hematomas e indícios de inflamação em camada serosa da porção proximal do reto.

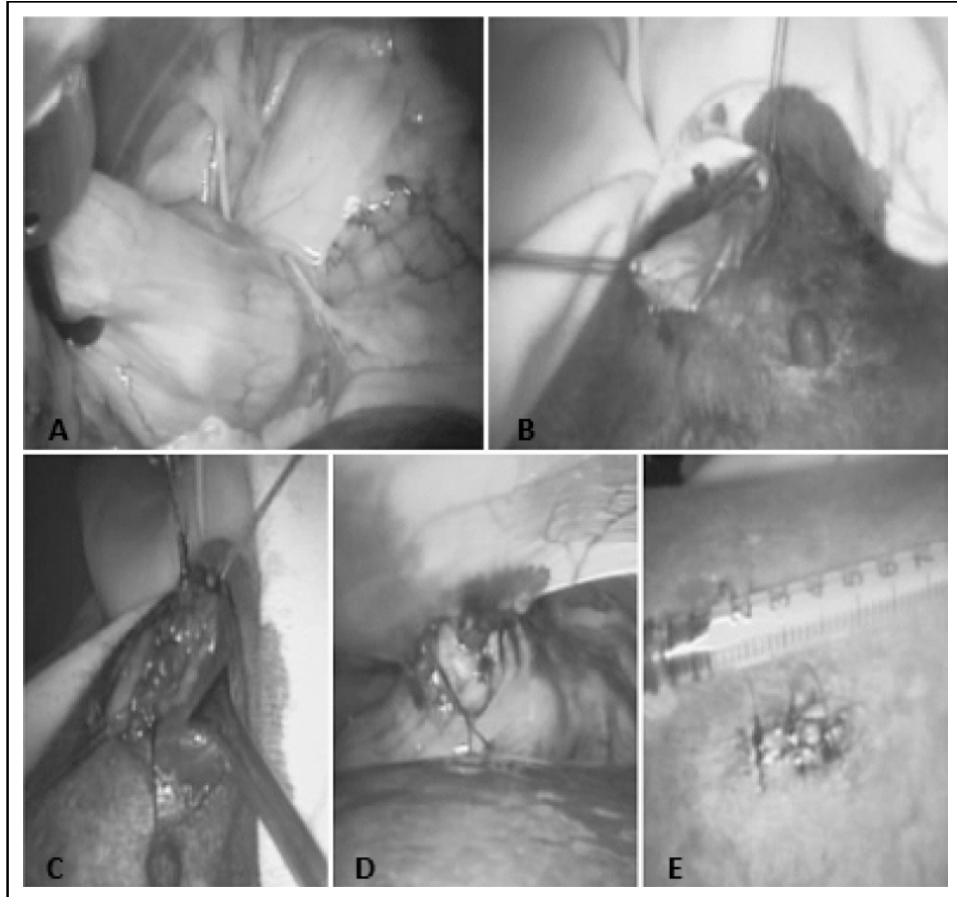

Figura 1 - etapas da colopexia videoassistida por dois portais. Em A, a redução do prolapso de reto pela tração cranial do cólon descendente; em B, a exposição do segmento utilizado para a colopexia através de suturas de arrimo, após ampliação da ferida de acesso paramediana do portal pré-púbico; $\mathrm{C}$ demonstra o aspecto externo após o final da colopexia, enquanto que, em $\mathrm{D}$, tem-se o aspecto interno, após redução do pneumoperitônio; e, em E, a extensão de ferida em pele após a aplicação de pontos isolados simples. 
Para a colopexia, o acesso pré-púbico foi ampliado cranialmente em $1,5 \mathrm{~cm}$ para a exposição do cólon descendente, sendo aplicadas suturas de arrimo cranial e caudal com fio cirúrgico ácido poliglicólico no 2-0 permitindo a remoção da pinça Babcock (Figura 1B). A seguir, efetuou-se uma incisão seromuscular em borda antimesentérica do cólon nessa região, com tamanho aproximado de $2,5 \mathrm{~cm}$, semelhante à realizada na parede muscular esquerda. A fixação do cólon descendente ao músculo reto abdominal e sua fáscia foi iniciada pela margem esquerda, através de sutura simples contínua com ácido poliglicólico nํㅡ 2-0, sendo esta técnica também utilizada na margem direita. Encerrada a colopexia (Figura 1C), os fios de reparo foram removidos, procedendo-se à síntese do folheto externo do reto abdominal com mesmo fio e padrão de sutura anteriormente descrito. Após a aproximação do tecido subcutâneo, nova avaliação intracavitária através do primeiro portal foi realizada (Figura 1D), confirmando o adequado posicionamento e fixação do cólon descendente. Procedeu-se à síntese cutânea com pontos simples interrompidos e fio mononáilon no $4-0$ em pele (Figura 1E), totalizando 55 minutos de procedimento cirúrgico.

O tratamento pós-operatório consistiu em administração de cloridrato de tramadol $\left(3 \mathrm{mg} \mathrm{kg}^{-1}, \mathrm{SC}\right.$, TID), dipirona sódica ( $25 \mathrm{mg} \mathrm{kg}^{-1}, \mathrm{SC}, \mathrm{TID}$ ) e meloxicam $\left(0,2 \mathrm{mg} \mathrm{kg}^{-1}, \mathrm{SC}, \mathrm{SID}\right)$ durante três dias. Não houve indícios de recidiva do prolapso retal ou episódios de tenesmo e disquesia após a intervenção cirúrgica. Seis meses após o procedimento, o paciente sofreu politraumatismo por atropelamento, com fraturas múltiplas em púbis, cuja conduta do clínico responsável foi conservadora. $O$ paciente manteve-se em condição de normoquesia e não demonstrou outras manifestações clínicas referentes aos prolapsos ocorridos anteriormente.

As complicações encontradas em procedimentos convencionais de colopexia consistem em herniações abdominais provenientes de deiscência de sutura, sem estarem relacionadas, especificamente, ao local da colopexia (POPOVITCH et al., 1994). No que se refere à colopexia laparoscópica, foram relatadas punção de baço durante a introdução da agulha de Veress, assim como enfisema de omento (BRUN et al., 2004a). Ambas as condições não foram observadas no presente relato, considerando que nenhum dos portais foi obtido "às cegas". Uma possível complicação, associada à colopexia tanto a convencional como a laparoscópica, consiste na perfuração da mucosa do cólon com consequente contaminação tecidual (HEDLUND \& FOSSUM, 2007), quer seja pela passagem inadvertida da agulha de sutura pela mucosa, ou devido à lesão não intencional dessa camada durante a incisão antimesentérica (BRUN et al., 2007a), a qual também não ocorreu no procedimento realizado.

Na dependência da técnica utilizada, o tempo cirúrgico da colopexia laparoscópica pode ser elevado, podendo atingir aproximadamente o dobro do tempo da cirurgia convencional (BRUN et al., 2004c). A técnica videoassistida se apresenta como alternativa no intuito de minimizar o número de portais, bem como o tempo operatório, além de isentar a necessidade de suturas intracorpóreas (BRUN et al., 2004b).

A colopexia incisional videoassistida pode ser considerada mais adequada se comparada a colopexia transparietal laparoscópica, que utiliza suturas apoiadas sobre a pele do paciente (BRUN et al., 2007a), evitando a formação de lesões dérmicas e nos planos mais profundos em locais de contato com os materiais utilizados para sustentar as suturas. Do ponto de vista da praticidade, grau de lesão tecidual promovida para o acesso e tempo operatório, a técnica descrita nesse relato é baseada nos princípios trazidos por RAWLINGS (2002) em gastropexias, e parece garantir resultados superiores à incisional laparoscópica com suturas. Na metodologia proposta por esse último autor, a partir de dois acessos (um para a óptica e outro para a pinça que irá apreender o órgão a ser fixado) é obtida fixação orgânica rápida e eficiente, dispensando a aplicação de suturas intracorpóreas que são tecnicamente complexas e necessitam de maior número de portais.

O procedimento de colopexia videoassistida apresenta aspectos relevantes e vantajosos em relação à colopexia laparoscópica. Quanto à sua aplicabilidade em animais jovens e de pequeno porte, nos quais é mais frequente a ocorrência de prolapso retal recidivante (WACHASK, 2002), o espaço de trabalho na cavidade abdominal obtido a partir do pneumoperitônio na colopexia laparoscópica é restrito e torna a aplicação de suturas intracorpóreas difícil, contribuindo para o aumento do tempo cirúrgico (BRUN et al., 2007a). Considerando as dimensões do paciente em questão, possivelmente uma óptica de $5 \mathrm{~mm}$ ou de diâmetro inferior, permitiriam adequada avaliação do segmento intestinal alterado e a escolha do melhor local de fixação do cólon. Optou-se pelo endoscópio de $10 \mathrm{~mm}$ e zero graus pela indisponibilidade de outras ópticas. Independentemente do equipamento disponível, é indicado que se avalie se a fixação intestinal ficou apropriada antes de se considerar o procedimento encerrado.

A colopexia incisional laparoscópica proporciona a formação de aderências permanentes do cólon à parede abdominal com características 
histológicas e resistência semelhante às da colopexia incisional por celiotomia (BRUN et al., 2004c). Neste caso, os autores acreditam que a aplicabilidade clínica da técnica videoassistida foi demonstrada por não haver sinais de recidiva após os sete primeiros dias do procedimento e por um período de seis meses, mesmo após a ocorrência de atropelamento e fraturas de púbis.

O procedimento de colopexia videoassistida com dois portais é efetivo na redução de prolapso retal, sem estar associado à recidiva dele. $\mathrm{O}$ presente relato reforça a adequação dessa técnica como uma alternativa viável à intervenção cirúrgica convencional na correção de prolapso retal recidivante em cães.

\section{REFERÊNCIAS}

BRUN, M.V. et al. Avaliação de dois diferentes fios de sutura para colopexia incisional laparoscópica em cães. Estudo experimental. Brazilian Journal of Veterinary Research and Animal Science, São Paulo, v.41, n.3, p.154-161, 2004a. Disponível em: <http://dx.doi.org/10.1590/S1413-95962004000300002>. Acesso em: 20 maio, 2011. doi: 10.1590/S141395962004000300002 .

BRUN, M.V. et al. Colopexia incisional por celiotomia ou transparietal auxiliada por laparoscopia em cães. Ciência Rural, Santa Maria, v.34, n.3, p.829-837, 2004b. Disponível em: <http://dx.doi.org/10.1590/S0103-84782004000300027>. Acesso em: 25 maio, 2011. doi: 10.1590/S010384782004000300027 .

BRUN, M.V. et al. Resistência à tração de colopexias incisionais realizadas por cirurgia laparoscópica ou celiotomia em cães. Ciência Rural, Santa Maria, v.34, n.3, p.839-
845, 2004c. Disponível em: <http://dx.doi.org/10.1590/ S0103-84782004000300028>. Acesso: 20 maio, 2011. doi: 10.1590/S0103-84782004000300028.

BRUN, M.V. et al. Colopexia laparoscópica com retalho de tela de polipropileno em cães. Arquivo Brasileiro de Medicina Veterinária e Zootecnia, Belo Horizonte, v.59, p.119-126, 2007a. Disponível em: <http://dx.doi.org/10.1590/ S0102-09352007000100020>. Acesso em: 16 maio, 2011. doi: 10.1590/S0102-09352007000100020.

BRUN, M.V. et al. Colopexia laparoscópica em cães com segmento de pericárdio homólogo conservado em glicerina a $98 \%$. Arquivo Brasileiro de Medicina Veterinária e Zootecnia, Belo Horizonte, v.59, p.1211-1218, 2007b. Disponível em: <http:// dx.doi.org/10.1590/S0102-09352007000500017>. Acesso em: 16 maio, 2011. doi: 10.1590/S0102-09352007000500017.

HEDLUND, C.H.; FOSSUM, T.W. Surgery of the digestive system. In: FOSSUM, T.W. Small animal surgery. St. Louis: Mosby, 2007. p.480-530.

FREEMAN, L.J. Laparoscopic colorectal surgery. In: Veterinary endosurgery. St. Louis: Mosby, 1998. p.144-151.

POPOVITCH, C.A. et al. Colopexy as a treatment for rectal prolapse in dogs and cats: a retrospective study of 14 cases. Veterinary Surgery, v.23, n.2, p.115-118, 1994

RAWLINGS, C.A. Laparoscopic-assisted gastropexy. Journal of the American Animal Hospital Association, v.38, n.1, p.15-19, 2002.

WACHASK, M.J. Rectal and anal prolapse. In: TILLEY, L.P.; SMITH JR., F.W.K. Tilley \& Smith: the 5-minute veterinary consult. Lippincott: Williams \& Wilkins, 2002. (CD-ROM) 